\title{
ACCEPTABILITY OF FINANCIAL INCENTIVES FOR ENCOURAGING UPTAKE OF HEALTHY BEHAVIOURS: A CRITICAL REVIEW USING SYSTEMATIC METHODS
}

Emma L Giles ${ }^{\mathrm{a}} \mathrm{PhD}$, Shannon Robalino ${ }^{\mathrm{a}} \mathrm{MSc}$, Falko F Sniehotta ${ }^{\mathrm{a}} \mathrm{PhD}$, Jean Adams ${ }^{\mathrm{a}} \mathrm{PhD}$, Elaine McColl ${ }^{\mathrm{b}} \mathrm{PhD}$.

${ }^{a}$ Institute of Health and Society, Newcastle University, Baddiley-Clark Building, Newcastle upon Tyne, Tyne and Wear, NE2 4AX, UK. Email addresses: e.l.giles@ncl.ac.uk; Shannon.robalino@ncl.ac.uk; falko.sniehotta@ncl.ac.uk; jean.adams@ncl.ac.uk

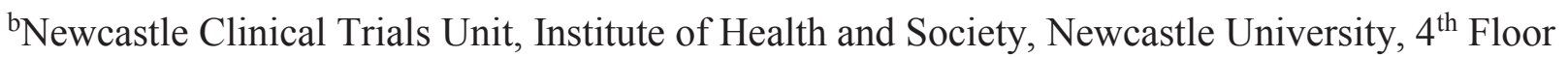
William Leech Building, The Medical School, Framlington Place, Newcastle upon Tyne, Tyne and Wear, NE2 4HH, UK. Email address: elaine.mccoll@ncl.ac.uk

Correspondence to: Emma L Giles, Institute of Health and Society, Newcastle University, Baddiley-Clark Building, Newcastle upon Tyne, Tyne and Wear, NE2 4AX, UK, Tel: +44 (0) 191208 4565, Email: e.1.giles@ncl.ac.uk.

\section{ETHICS APPROVAL}

Ethical approval was not required for this secondary analysis of published work.

\section{FINANCIAL DISCLOSURE}

No financial disclosures were reported by the authors of this paper.

Word count abstract: 199

Word count main text: 4837

Number of pages: 29

Number of figures: 3

Number of boxes: 5

Number of tables: 3

Number of appendices: 2 


\begin{abstract}
Objective

Financial incentives are effective in encouraging healthy behaviours, yet concerns about acceptability remain. We conducted a systematic review exploring acceptability of financial incentives for encouraging healthy behaviours.
\end{abstract}

\title{
Method
}

Database, reference, and citation searches were conducted from the earliest available date to October 2014, to identify empirical studies and scholarly writing that: had an English language title, were published in a peer-reviewed journal, and explored acceptability of financial incentives for health behaviours in members of the public, potential recipients, potential practitioners or policy makers. Data was analysed using thematic analysis.

\section{Results}

Eighty one papers were included: 59 pieces of scholarly writing and 22 empirical studies, primarily exploring acceptability to the public. Five themes were identified: fair exchange, design and delivery, effectiveness and cost-effectiveness, recipients, and impact on individuals and wider society. Although there was consensus that if financial incentives are effective and cost effective they are likely to be considered acceptable, a number of other factors also influenced acceptability.

\section{Conclusion}

Financial incentives tend to be acceptable to the public when they are effective and costeffective. Programmes that benefit recipients and wider society; are considered fair; and are delivered to individuals deemed appropriate are likely to be considered more acceptable. 


\section{INTRODUCTION}

Poor engagement in healthy behaviours is a key determinant of morbidity and mortality and results in social, healthcare and economic costs (Swann et al., 2010). Despite efforts to encourage healthy behaviours, unhealthy behaviours remain common (Department of Health, 1998, Department of Health, 2004).

Providing financial incentives to encourage healthy behaviours is one method to encourage uptake of healthy behaviours. Health promoting financial incentives (HPFI) are cash or cashlike rewards provided contingent on performance of healthy behaviours (Adams et al., 2013). Our recent systematic review of the effectiveness of HPFI found that financial incentives were around 1.5 to 2.5 times more effective for promoting healthy behaviours than no intervention or usual care (Giles et al., 2014).

In the United States of America (USA), the 2010 Affordable Care Act allowed employers to offer rewards, or impose penalties, for those meeting healthy behaviour targets such as quitting smoking (Madison, Volpp and Halpern, 2011). Similar HPFI operate within the German social health insurance scheme (Schmidt, 2008). In the United Kingdom (UK), the current government have signalled their interest in using HPFI as part of their 'nudge' agenda (Department of Health, 2010). Despite this empirical and political support for HPFI, the acceptability of HPFI interventions has been questioned (Popay, 2008, Cookson, 2008).

Acceptability of public health interventions must be considered from the point of view of a number of stakeholders. In relation to HPFI, these include potential recipients, professionals and policy makers responsible for intervention implementation, and the general public who may finance interventions through taxation. All of these groups must be willing and able to engage with an intervention (Craig et al., 2008), if HPFI are to be widely implemented.

Acceptability of interventions can be explored in primary research. However, scholarly critique also constitutes valuable evidence, as it is likely to reflect the opinion of important stakeholders. We conducted a review to bring together both empirical evidence and scholarly writing on the acceptability of HPFI. We were particularly interested in what features of HPFI have been 
identified as potentially acceptable and unacceptable, the range of methods that have been used to determine acceptability, and the range of individuals in which acceptability has been explored.

\section{METHODS}

This review is reported in accordance with the Preferred Reporting Items for Systematic Reviews (PRISMA) guidelines (Moher et al., 2009) (Appendix A). Given the non-standard nature of the inclusion criteria and data collected, we did not register our protocol in advance. A copy of the apriori protocol is available from the authors on request. No substantive changes to the protocol were made.

\section{Information sources}

Electronic databases were searched from the earliest date available (indicated in brackets below) until $1^{\text {st }}$ October 2014, for primary research and scholarly writing, exploring the acceptability of HPFI. Databases searched were: Medline (1946), Embase (1980), Web of Knowledge (1970), Cumulative Index to Nursing and Allied Health Literature (1981), PsycINFO (1806), Applied Social Science Index and Abstracts (1970), Sociological Abstracts (ProQuest, 1952), Scopus (1960), The Philosopher's Index (OVID, 1940), the Cochrane library (Issue 3), Social Science Citation Index (1970) and the International Bibliography for the Social Sciences (1951). An example of the full electronic search used in Medline is shown in Appendix B. The search was adapted as required for other databases. All studies included in our systematic review of the effectiveness of HPFI (Giles et al., 2014) were considered for inclusion, and reference and citation searches of included papers as well as relevant reviews identified in the search were conducted.

\section{Eligibility criteria}

Papers that met the following criteria were included: had an English language title; were published in a peer-reviewed journal; and explored the acceptability of HPFI from the perspective of: members of the public, potential recipients, potential practitioners who may be involved in delivering HPFI, or policy makers. Specifically, all included papers used the term 'acceptable', 'accept', 'acceptability', 'unacceptable' 'ethics', 'moral' or some variation of these. HPFI were defined as cash or cash-like rewards, which were provided contingent on change in a 
healthy behaviour. Only papers exploring acceptability of HPFI delivered to adults living in high income economies (defined by the World Bank as those countries with a Gross National Income of $\$ 12,276$ or more per capita in 2010) were included. Empirical studies were defined as papers reporting primary data. Scholarly writing was defined as referenced writing; for example, position papers and editorials (Schmidt, 2008, Popay, 2008, Madison, Volpp and Halpern, 2011, Cookson, 2008).

\section{Paper selection and data collection}

After exclusion of duplicates, one researcher (ELG) screened titles and excluded those definitely not relevant. Next, the same researcher screened remaining titles and abstracts, again excluding those definitely not relevant. Finally, remaining full texts were screened by two researchers independently (ELG \& JA) to identify those meeting the inclusion criteria. If in doubt, papers were retained at any stage for inspection by both reviewers, with disagreements resolved by discussion.

\section{Quality assessment}

Quality assessment of scholarly writing was not undertaken as no appropriate tool could be identified. The quality of empirical research papers using qualitative methods was assessed using a tool developed for this purpose (Barnard et al., 2010, Petticrew and Roberts, 2005). Papers using quantitative methods were assessed using the Effective Public Health Practice Project (EPHPP) Quality Assessment Tool (Effective Public Health Practice Project, 2009). Two researchers (ELG and JA) conducted quality appraisal independently and disagreements were resolved by discussion. Papers using mixed methods were appraised using both tools as appropriate.

\section{Synthesis of results}

Data was extracted by one researcher (ELG) and summarised in tabular form. Empirical studies were considered to be too heterogeneous for meta-analysis. Although three studies did use, or adapt, the same questionnaire, adaptations were so substantial that there was too little combinable data to justify meta-analysis ( Long, Helweg-Larsen and Volpp, 2008, Lynagh et al., 2011). Instead, thematic synthesis of all included papers was undertaken, focusing on issues 
related to the acceptability of HPFI. In this, findings from empirical studies were integrated with issues discussed in scholarly writing.

The full texts of included papers were uploaded into NVivo 10 QSR International software and thematically coded (Barnett-Page and Thomas, 2009). The first stage involved close reading and identification of codes (Bryman, 2004, Strauss, 2003). Next, papers were re-read and codes checked to ensure no data was missed. Thirdly, codes were sorted into categories, with some codes being merged with others or re-named, and new codes emerging. Finally, codes were interpreted in light of the research questions. The first three stages were completed by one researcher (ELG). The final stage was led by one researcher (ELG) with discussion and verification by a second (JA).

Once the coding was finalised a narrative was built by describing, linking and interpreting the codes. The themes are presented in the results, with representative quotes illustrating each theme presented in boxes. In addition, these quotes provide 'evidence' to support our results and justification for the conclusions we draw. Each quotation included in the boxes is identified both by a formal citation, and as either an 'empirical paper' or 'scholarly writing' to clarify the source of different statements.

A citation map was drawn to show the citation links between included papers. This allowed key papers in the corpus of included papers to be identified.

\section{RESULTS}

Eighty one papers met the inclusion criteria: 22 empirical studies (Allan, Radley and Williams, 2012, Arterburn et al., 2008, Bonevski, Bryant and Paul, 2011, Bonevski et al., 2012, Cameron and Ritter, 2007, Ducharme et al., 2010, Hoddinott et al., 2014, Kim et al., 2011, Long, HelwegLarsen and Volpp, 2008, Luyten et al., 2013, Lynagh et al, 2011, Mantzari, Vogt and Marteau, 2012, Meads et al., 2013, Meredith, Grabinski and Dallery, 2011, Mhurchu et al., 2011, Park, Mitra and Asch, 2012, Parke et al., 2013, Promberger et al., 2011, Promberger, Dolan and Marteau, 2012, Raiff et al., 2013, Ritter and Cameron, 2007, Thomson et al., 2012) and 59 pieces of scholarly writing (see Figure 1 and Tables 1 and 2) (Ashcroft, 2011, Ashcroft, Marteau and 
Oliver, 2008, Aveyard and Bauld, 2011, Axtell-Thompson, 2012, Blacksher, 2008, BlumenthalBarby and Burroughs, 2012, Burry, 2006, Cawley, 2014, Cookson, 2008, Dreger, 2012, Donatelle et al., 2004, Grant, 2002, Grant, 2006, Goel, 2012, Halpern, Madison and Volpp, 2009, Haveman, 2010, Higgins et al., 2012, Horwitz et al., 2013, Kennedy, 2012, Klein, 2012, Klein and Karlawish, 2010, Kowal, 2006, Lawson and Howard, 2012, Lesser and Puhl, 2014, Lewis, 2008, Loeppke, 2012, London et al., 2012, Lunze and Paasche-Orlow, 2013, Luyten et al., 2011, Madison, Volpp and Halpern, 2011, Malone and Jason, 1990, Marteau, Ashcroft and Oliver, 2009, Marteau, Oliver and Ashcroft, 2008, Meredith et al., 2014, O’Donnell, 2012, Oliver, 2009, Oliver, 2012, Oliver and Brown, 2012, Pearson and Lieber, 2009, Petry, 2010, Popay, 2008, Robison, 1998, Roozen, 2009, Schmidt, 2008, Schmidt, 2012, Schmidt, Gerber and Stock, 2009, Schmidt, Asch and Halpern, 2012, Schmidt, Voigt and Wikler, 2009b, Serxner, 2013, Sindelar, 2008, Stephens, 2014, ten Have et al., 2013, Terry, 2013, Terry and Anderson, 2011, Voigt, 2012, Volpp and Galvin, 2014, Volpp et al., 2009, Volpp, Galvin and Loewenstein, 2011, $\mathrm{Wu}, 2012)$

A further three papers were included at the title and abstract stage but none of these texts could be located (Botelho, 2012, McCormack, 1996, Tuten et al., 2012) and they were excluded from the review.

Empirical studies collected data using surveys $(n=13)$, including one Discrete Choice Experiment (Promberger, Dolan and Marteau, 2012); (Arterburn et al., 2008, Bonevski et al., 2012, Hoddinott et al., 2014, Kim et al., 2011, Long, Helweg-Larsen and Volpp, 2008, Luyten et al., 2013 Lynagh et al., 2011, Meads et al., 2013, Meredith, Grabinski and Dallery, 2011, Park, Mitra and Asch, 2012, Promberger et al., 2011, Ritter and Cameron, 2007, Raiff et al., 2013), individual semi-structured interviews ( $\mathrm{n}=3$ ) ( Allan, Radley and Williams, 2012, Cameron and Ritter, 2007, Mantzari, Vogt and Marteau, 2012), mixed methods ( $\mathrm{n}=4)$ (Bonevski, Bryant and Paul, 2011, Ducharme et al., 2010, Mhurchu et al., 2011, Thomson et al., 2012) and one thematic analysis of media coverage (Parke et al., 2013). Study populations were primarily members of the public (n=17) (Allan, Radley and Williams, 2012, Arterburn et al., 2008, Bonevski et al., 2012, Hoddinott et al., 2014, Kim et al., 2011, Long, Helweg-Larsen and Volpp, 2008, Luyten et al., 2013, Lynagh et al., 2011, Mantzari, Vogt and Marteau, 2012, Mhurchu et al., 2011, Park, 
Mitra and Asch, 2012, Promberger et al., 2011, Promberger, Dolan and Marteau, 2012, Raiff et al., 2013, Meads et al., 2013, Meredith et al., 2014, Thomson et al., 2012), or health professionals and managers (n=3) (Cameron and Ritter, 2007, Ducharme et al., 2010, Ritter and Cameron, 2007). One study included a mixed population of clinicians, health professionals, administrative staff and members of the public (Bonevski, Bryant and Paul, 2011), and one study reported the content of media coverage of relevant information (Parke et al., 2013).

Quality appraisal of empirical studies is summarised in Figure 2 and Table 3. Qualitative studies were largely rated as 'good'. However many quantitative studies did not include a clearly representative sample, justify their sample size, or provide good evidence of generalisability of findings. Acceptability is, by its nature, subjective. Nevertheless, no aspects of reliability or validity of survey instruments were discussed or reported. Three studies used adaptations of the same survey instrument (Long, Helweg-Larsen and Volpp, 2008, Lynagh et al., 2011).

\section{Citation mapping}

Figure 3 shows the number of times that included papers were cited by other included papers. Forty two included papers cited at least one other included paper, and 40 were cited by at least one other included paper. The most frequently cited papers were Marteau, Ashcroft and Oliver (2009) (Marteau, Ashcroft and Oliver, 2009) - a piece of scholarly writing in a high profile general medical journal - and Long, Helweg-Larsen and Volpp (2008) (Long, Helweg-Larsen and Volpp, 2008) - an empirical study describing the survey instrument used in subsequent research.

\section{What makes HPFI acceptable or unacceptable?}

The thematic synthesis identified five themes: fair exchange, design and delivery, effectiveness and cost-effectiveness, recipients, and impact on individuals and wider society. Most included papers explored acceptability from the point of view of the general public. Where this was not the case, this is highlighted in Tables 1 and 2 and in the discussion below.

\section{Theme 1: Fair exchange}

Health promoting financial incentives involve an exchange between the recipient and the incentive provider. The recipient benefits from both the behaviour incentivised and the incentive 
offered, whilst the provider benefits from the improvement in public health brought about by the change in behaviour. This 'fair exchange' was identified as an important aspect of acceptability by a number of authors (see Box 1a).

Some authors of included papers argued that if parties act voluntarily, the mutual benefits of HPFI make them acceptable. This was the case when HPFI offset the opportunity costs of giving up non-healthy behaviours, providing additional motivation for behaviour change (see Box 1b).

Other authors argued that as the target recipients of HPFI are often vulnerable groups, who are most in need of financial resources, the choice to engage is rarely 'voluntary'. Instead, these authors view HPFI as coercive (Blumenthal-Barby and Burroughs, 2012). The 'fair exchange' of HPFI is also contested by some who argue that HPFI discriminate against those who pursue healthy behaviours without the need for incentives and those who are unable to comply with behavioural change programmes (see Box 1c) (Schmidt, Voigt and Wikler, 2009).

\section{Theme 2: Design and delivery of HPFI}

Health promoting financial incentives are complex interventions that can vary in at least nine domains (Adams et al., 2013). The design and delivery of HPFI, in part, contributed to whether they were perceived as acceptable or not. Additionally, if HPFI were found to be effective, they tended to be more accepted. In general, if HPFI are safe, focused on the recipients, minimise intrusion into their daily lives, and are of an effective - but not too large - amount, then they are viewed as acceptable.

Two particular concerns were raised in reference to appropriate providers of HPFI. Firstly, empirical research has found that many socio-economically disadvantaged individuals are not willing to accept government funded HPFI under any circumstances - although reasons for this have not been explored. Secondly, the potentially negative impact of HPFI administered by doctors on doctor-patient relationships is considered problematic (see Box 2a).

Incentives which are provided with higher frequency (Volpp et al., 2011, Volpp et al., 2009) and nearer to the point of behaviour were considered more acceptable (see Box 2b) (Schmidt, Asch and Halpern, 2012). 
Providing flexible incentives, particularly as cash, gives recipients more choice over how they use incentive payments and may be preferred by recipients (Schmidt, Gerber and Stock, 2009). However, shopping vouchers were viewed as more acceptable to both the general public and practitioners involved in helping disadvantaged smokers quit (Bonevski, Bryant and Paul, 2011, Mhurchu et al., 2011), as they provide some control on recipients' spending. Similarly, there were arguments in included papers favouring both incentives for process behaviours (e.g. attending behaviour change sessions) and for behavioural outcomes (e.g. smoking cessation) (Robison, 1998, Schmidt, Asch and Halpern, 2012, Volpp et al., 2009). These contrasting opinions likely reflect the varying population groups in which acceptability of HPFI was explored (see Box 2c).

\section{Theme 3: Effectiveness and cost-effectiveness of HPFI}

There was strong consensus that if HPFI have been demonstrated to be effective and costeffective (Volpp et al., 2009), they are more likely to be acceptable. One included empirical paper confirmed this relationship between effectiveness and acceptability, reporting that the acceptability of hypothetical HPFI to members of the public increased as stated effectiveness increased (see Box 3a) (Promberger, Dolan and Marteau, 2012).

In contrast, some arguments in favour of cost-effectiveness were highly simplistic. For example, one author argued that HPFI do not incur financial costs to providers until behaviour change has occurred. This ignores the costs of, for example, front line staff introducing and explaining programmes to participants (Giles et al., 2014, Johnston and Sniehotta, 2010). There is growing evidence that HPFI can be as effective as other behaviour change strategies (Cahill and Perera, 2008, Giles et al., 2014, Kane et al., 2004, Kavanagh, Stansfield and Thomas, 2009), but little evidence for cost-effectiveness has been published (see Box 3b).

A common criticism of HPFI was that they offer only short term motivation. Additionally, external motivators are argued to reduce internal motivation for change, hence offering limited support for long term change once HPFIs are removed (Robison, 1998). Some authors argue that these issues are inherent limiters of effectiveness and hence acceptability. Others argue that this 
only means HPFI need to be used within the context of a wider behaviour change and maintenance programme (see Box 3c).

Theme 4: Recipients of HPFI

Pregnant women and disadvantaged groups were generally thought of as appropriate, or deserving, groups for HPFI. However, more vulnerable groups were also identified as at most risk of being coerced into behaviour change by HPFI. There was a consistent finding that individuals currently engaging in behaviours identified as potential targets for HPFI rated incentives as more acceptable than those who did not stand to gain immediately from HPFI (see Box 4a).

One paper argued that American drug and alcohol clinicians are more accepting of HPFI than Britons or Australians because of relevant international differences in the transactional nature of healthcare provision (see Box 4b) (Ritter and Cameron, 2007).

Some concern was raised with providing cash incentives to help control substance misuse as rewards could be used to fund the very behaviour it is designed to prevent (Roozen, 2009). In practice, programmes circumvent this by providing vouchers that can be exchanged for a limited range of goods and services, rather than cash, and this likely influences why vouchers tend to be considered more acceptable to both the public and drug and alcohol practitioners (see Box 4c) (Cameron and Ritter, 2007, Oliver and Brown, 2012, Parke et al., 2013, Petry, 2010).

\section{Theme 5: Impact of HPFI on individuals and wider society}

Some authors argued that HPFI can encourage individuals to take responsibility for themselves, thereby promoting autonomy (Marteau, Ashcroft and Oliver, 2009). This assumes that all individuals wish to pursue healthy behaviours, and all that holds them back is the absence of a short term reward (see Box 5a). The large number of other barriers to healthy behaviours that have been identified, suggests that this is simplistic (Axtell-Thompson, 2012). In contrast, some authors argued that HPFI are paternalistic and undermine individual autonomy by placing undue emphasis on bringing one's behaviour into line with that deemed acceptable by providers of HPFI (see Box 5b) (Halpern, Madison and Volpp, 2009, Marteau, Ashcroft and Oliver, 2009). 
Some commentators raised the possibility that HPFI may provide perverse incentives to engage in unhealthy behaviours or encourage individuals to 'game the system' (Aveyard and Bauld, 2011, Axtell-Thompson, 2012). Although there is some evidence from Honduras (Lagarde, Haines and Palmer, 2007) that the introduction of HPFI associated with a number of 'well child' behaviours was associated with an increase in the fertility rate, documented accounts of widespread 'gaming the system' are rare (see Box 5c).

The potential for a perpetuating cycle of personal failure was also discussed. Lack of success in behaviour change, emphasised by failure to gain a reward, may lead to demotivation and even greater difficulty in future attempts at behaviour change.

Some authors proposed that HPFI offer the potential to enhance community spirit by providing opportunities to engage in collective action to reduce the negative impacts of individual lifestyle choices and behaviours (Ashcroft, Marteau and Oliver, 2008). Alongside the perception that HPFI are particularly attractive to more disadvantaged individuals, this is suggested as a potential mechanism for decreasing socio-economic inequalities in health (see Box 5d) (Voigt, 2012). In contrast, other authors argued that, as barriers to change are fewer in more advantaged communities, HPFI may be most effective in these groups and so exacerbate health inequalities (Oliver, 2009). There is growing evidence that a range of public health and health care interventions that rely on voluntary behaviour change are more effective in more affluent groups leading to a widening of inequalities (see Box 5e) (Capewell and Graham, 2010, White, Adams and Heywood, 2009).

\section{DISCUSSION}

\section{Statement of principal findings}

This is the first systematic review to focus on the acceptability of HPFI that we are aware of. Of 81 papers that met the inclusion criteria, less than a third presented empirical data. Most empirical studies involved surveys of the public. In-depth qualitative work and studies across a range of stakeholders were rare or absent. 
Issues concerning acceptability of HPFI fell into five themes: fair exchange, design and delivery, effectiveness and cost-effectiveness, recipients, and impact on individuals and wider society. Throughout, there were contradictions in included papers. There was a strong underlying consensus that if HPFI are shown to be effective and cost-effective then they are likely to be considered acceptable, but other factors also influenced acceptability - not always in a predictable way. A lack of relevant data meant we were not able to come to any clear conclusions on whether acceptability varied according to the nature of the behaviour incentivised or the population rating acceptability.

\section{Strength and weaknesses of included work}

The majority of empirical papers included in the review used a quantitative or mixed qualitative/quantitative approach, meaning that larger samples (largely using convenience sampling) were included, but depth of opinion was lacking. Acceptability is a complex phenomenon and it is likely that more in-depth, qualitative research will shed more light on these complexities than survey-based quantitative research.

Although more general discussion of the acceptability of HPFI was provided in the 59 pieces of scholarly writing, few of these drew consistently on the empirical papers (see Figure 3) meaning that this scholarly critique was not always evidence-informed. However, some of these pieces of scholarly writing were published in high profile empirical journals and are likely to have been widely read, and considered to be grounded in empirical evidence. Although empirical data is not the only source of knowledge, nor did scholarly writing tend to be in-depth philosophical or ethical debates. As such, we felt the level of consideration of acceptability of HPFI across all included papers lacked depth.

Whilst quality appraisal was undertaken for the empirical papers, this was not possible for the scholarly writing as no relevant tool could be located. Formal quality appraisal identified that qualitative components of empirical studies tended to be medium or high quality. Quantitative components were mostly poor in terms of representativeness and generalisability of the sample, justification of sample size and reliability and validity of tools. In some ways this reflects the 
nature of the work included in the review - acceptability is a subjective concept and criterion validity of tools is hard to confirm.

There is a dearth of empirical work on the acceptability of HPFI, particularly the specifics of when HPFI are and are not acceptable and from the perspective of a range of stakeholders. Whilst views from members of the public were explored in 17 of the 22 empirical papers, only a minority focused on the views of health practitioners and organisations tackling health behaviours $(n=4)$. Scholarly writing tended to explore acceptability from the perspective of the general public, or from a non-specific viewpoint, where the specifics of 'for whom' acceptability was being considered was not clear. No attempt was made in any included papers to explore whether and how acceptability varied according to socio-demographic characteristics of members of the public. If HPFI are to be targeted to particular population groups, then understanding which groups might find them most acceptable would be valuable. Similarly, a wide variety of stakeholders are likely to be involved in commissioning, design and delivery of any HPFI, and understanding acceptability in these groups would help with smooth implementation (Craig et al., 2008).

Empirical research was also undertaken in a narrow range of countries, with the main settings being the UK $(n=7)$, USA $(n=7), \operatorname{UK}$ and USA $(n=1)$, Australia $(n=5)$, The Netherlands $(n=1)$ and New Zealand $(n=1)$. Whilst it has been suggested that acceptability may vary internationally, and be related to differences in how health care is currently funded (Ritter A, 2007), there is little empirical evidence to support this conclusion. Further work exploring this would be valuable to help policy makers and practitioners understand if acceptability data is generalisable or not across countries. Finally, the disciplines of those undertaking the empirical research were fairly narrow, being public health $(n=9)$, medicine and psychology $(n=11)$, and social science and sociology $(n=2)$. Individuals from some disciplinary backgrounds may be more sympathetic to HPFI than others, but it was not possible to explore this.

\section{Strengths and weaknesses of this review}

We believe that all papers meeting the inclusion criteria were identified. Three papers that were included at the title and abstract stage could not be located and so were excluded from the review 
(Botelho, 2012, McCormack, 1996, Tuten et al., 2012). Nonetheless, we feel that data saturation was achieved. Using thematic analysis gave greater flexibility allowing themes to emerge from the data. The lack of an a-priori theoretical framework is, however, considered a disadvantage of thematic analysis by some (Braun and Clarke, 2006).

A wide range of arguments and counterarguments were found in relation to the acceptability of HPFI. The heterogeneity and contradictions in the included papers highlights the contested nature of HPFI. Whilst we were able to identify some aspects of HPFI that influence acceptability, the exact nature of an 'acceptable' HPFI is not clear and appears to be contextspecific.

Including both quantitative and qualitative empirical work in the same systematic review is unusual. It is particularly rare to include non-empirical work in a systematic review. As such, there was little in the way of guidance available to us to help guide our review. We drew on aspects of standard systematic reviewing methodology (Petticrew and Roberts, 2005, The Cochrane Collaboration, 2011), as well as meta-ethnography in developing our methods (Britten et al., 2002, Noblit, Hare and Van Maanen, 1988). Whilst we believe we have conducted a rigorous and thorough review, other approaches may have been equally appropriate.

In conducting this review, we adopted the perspective that both empirical findings and scholarly writing were equally valid. Although we found it interesting that scholarly writing did not appear to draw strongly from empirical findings, empirical research is not the only source of knowledge. Multidisciplinary approaches are required to gain a holistic appreciation of the complexity of acceptability of HPFI.

\section{Interpretation of findings and implications for policy, practice and research}

We found a variety of issues surrounding acceptability of HPFI relating to fair exchange, design and delivery, effectiveness and cost-effectiveness, recipients, and impact on individuals and wider society. However, disagreements in the literature exist in all areas. The one consistent finding was that demonstrated effectiveness and cost-effectiveness are key determinants of acceptability. 
Although HPFI are sometimes viewed as more contentious than other health behaviour change interventions, the requirement that an intervention must be effective and cost-effective to be acceptable is likely to be universal. As there is growing evidence of effectiveness of HPFI (Cahill and Perera, 2008, Giles et al., 2014, Kane et al., 2004, Kavanagh, Stansfield and Thomas, 2009, Paul-Ebhohimhen and Avenell, 2008, Wall et al., 2006), this finding also suggests that better communication of the existing effectiveness evidence to all relevant stakeholders could increase the acceptability of HPFI. Further work is required to determine the best methods of communicating this evidence. Future empirical research on the long term effectiveness of HPFI, and whether they undermine intrinsic motivation, would also be helpful to respond to concerns in these areas (Thomson et al., 2014).

Given the lack of qualitative data we found, it is difficult to get a clear idea of the depth and strength of feeling towards HPFI. Similarly there remains little evidence on the particular types, format, size, and scheduling of financial incentives, which are most acceptable (Cahill and Perera, 2008, Giles et al., 2014, Kane et al., 2004, Kavanagh, Stansfield and Thomas, 2009, Paul-Ebhohimhen and Avenell, 2008, Wall et al., 2006). Future work would benefit from adopting qualitative approaches to explore acceptability in-depth with the public, practitioners who may be involved in delivering HPFI, and policy makers who may have to defend their implementation. In addition, large scale quantitative surveys with population-representative samples would help determine if certain socio-demographic characteristics are associated with the acceptability of HPFI.

\section{CONCLUSION}

The available evidence suggests that HPFI are acceptable when they are considered effective and cost-effective; if they provide benefits to individual recipients and wider society; when they are considered fair; and when they are delivered to individuals who are deemed acceptable recipients. Other factors also influenced acceptability, but not always in a predictable way Disagreement exists in relation to the specific aspects of these issues that make HPFI acceptable. Further research is required to explore acceptability across a wider range of stakeholders, and how acceptability varies according to the nature of HPFI interventions and the populations rating 
acceptability. Studies using both in-depth qualitative methods, and quantitative survey methods in population-representative cohorts, are required to address these gaps.

\section{ACKNOWLEDGEMENTS}

This work is produced under the terms of a Career Development Fellowship research training fellowship issued by the NIHR to JA, grant number: CDF-2011-04-001. The views expressed are those of the authors and not necessarily those of the NHS, The National Institute for Health Research or the Department of Health. JA \& ELG are funded in part, and FFS is funded in full by Fuse: the Centre for Translational Research in Public Health, a UKCRC Public Health Research Centre of Excellence. Funding for Fuse from the British Heart Foundation, Cancer Research UK, Economic and Social Research Council, Medical Research Council, the National Institute for Health Research, under the auspices of the UK Clinical Research Collaboration, is gratefully acknowledged. The funders had no role in study design, data collection and analysis, decision to publish, or preparation of the manuscript.

\section{CONFLICT OF INTEREST STATEMENT}

The authors declare that there are no conflicts of interest. The study sponsor did not have a role in the study design; collection, analysis, and interpretation of data; writing the report; and the decision to submit the report for publication. 


\section{REFERENCES}

ADAMS, J., GILES, E. L., MCCOLL, E. \& SNIEHOTTA, F. F. 2013. Carrots, sticks and health behaviours: a framework for documenting the complexity of financial incentive interventions to change health behaviours. Health Psychol Rev, 8, 3, 286-295.

ALLAN, C., RADLEY, A. \& WILLIAMS, B. 2012. Paying the price for an incentive: An exploratory study of smokers' reasons for failing to complete an incentive based smoking cessation scheme. J Health Serv Res Policy, 17, 212 - 218.

ARTERBURN D, WESTBROOK, E. O., WIESE, C. J., LUDMAN, E. J., GROSSMAN, D. C., FISHMAN, P. A., FINKELSTEIN, E. A., JEFFERY, R. W. \& DREWNOWSKI, A. 2008. Insurance coverage and incentives for weight loss among adults with metabolic syndrome. Obes, 16, 70-76.

ASHCROFT, R. E. 2011. Personal financial incentives in health promotion: where do they fit in an ethic of autonomy. Health Expect, 14, 191-200.

ASHCROFT, R. E., MARTEAU, T. M. \& OLIVER, A. 2008. Payment to look after health: incentive mechanisms require deeper understanding. BMJ, 337, a1135.

AVEYARD. P. \& BAULD, L. 2011. Incentives for promoting smoking cessation: what we still do not know. Cochrane database of systematic reviews (Online), ED000027.

AXTELL-THOMPSON, L. 2012. Nudge ethics for health plans. Am J Bioeth, 12, 24-25.

BARNARD, K., THOMAS, S., ROYLE, P., NOYES, K. \& WAUGH, N. 2010. Fear of hypoglycaemia in parents of young children with type 1 diabetes: a systematic review. BMC Pediatr, 10, 18.

BARNETT-PAGE, E. \& THOMAS, J. 2009. Methods for the synthesis of qualitative research: a critical review. BMC Med Res Methodol, 9, 1-11.

BLACKSHER, E. 2008. Carrots and sticks to promote healthy behaviors: a policy update. Hastings Cent Rep, 38, 13-6.

BLUMENTHAL-BARBY, J. S. \& BURROUGHS, H. 2012. Seeking better health care outcomes: The ethics of using the "nudge". Am J Bioeth, 12, 1-10. 
BONEVSKI, B., BRYANT, J., LYNAGH, M. \& PAUL C. 2012. Money as motivation to quit: a survey of a non-random Australian sample of socially disadvantaged smokers' views of the acceptability of cash incentives. Prev Med, 55, 122-126.

BONEVSKI, B., BRYANT, J. \& PAUL, C. 2011. Encouraging smoking cessation among disadvantaged groups: a qualitative study of the financial aspects of cessation. Drug Alcohol Rev, 30, 411-418.

BOTELHO, R. 2012. Motivating healthy behavior. Sahler, Olle Jane Z [Ed], 301-307.

BRAUN, V. \& CLARKE, V. 2006. Using thematic analysis in psychology. Qual Res Psychol, 3, 77101.

BRITTEN, N., CAMPBELL, R., POPE, C., DONOVAN, J., MORGAN, M. PILL, R. (2002) Using meta ethnography to synthesise qualitative research: a worked example. J Health Serv Res Policy, 7, 209.

BRYMAN, A. 2004. Social research methods, Oxford, Oxford University Press.

BURRY, J. N. 2006. Mutual obligation and Indigenous health: thinking through incentives and obligations. Med J Austr, 185, 181-182.

CAHILL, K. \& PERERA, R. 2008. Quit and win contests for smoking cessation. Cochrane Database of Systematic Reviews 3, CD004986.

CAMERON, J. \& RITTER, A. 2007. Contingency management: perspectives of Australian service providers. Drug Alcohol Rev, 26, 183-189.

CAPEWELL, S. \& GRAHAM, H. 2010. Will cardiovascular disease prevention widen health inequalities? PloS Med, 7(8): e1000320. doi:10.1371/journal.pmed.1000320

CAWLEY, J. 2014. The Affordable Care Act permits greater financial rewards for weight loss: a good idea in principle, but many practical concerns remain. J Policy Anal Manage, 33, 810-20.

COOKSON, R. 2008. Should disadvantaged people be paid to take care of their health? Yes. . BMJ, 337, 141.

CRAIG, P, DIEPPE, P., MACINTYRE S., MICHIE, S., NAZARETH, I. \& PETTICREW, M. 2008. Developing and evaluating complex interventions: the new Medical Research Council guidance. BMJ, 337, a1655. 
DEPARTMENT OF HEALTH. 1998. Our healthier nation: a contract for health. London: Her Majesty's Stationery Office.

DEPARTMENT OF HEALTH. 2004. Choosing health: making healthier choices easier. London: Her Majesty's Stationery Office.

DEPARTMENT OF HEALTH. 2010. Healthy lives, healthy people: our strategy for public health in England. London: Her Majesty's Stationery Office.

DONATELLE, R. J., HUDSON, D., DOBIE, S., GOODALL, A., HUNSBERGER, M., OSWALD, K. 2004. Incentives in smoking cessation: status of the field and implications for research and practice with pregnant smokers. Nicotine Tob Res, 6, S163-S179.

DREGER, M. 2012. Guidance for a reasonably designed, employer-sponsored wellness program using outcomes-based incentives. J Occup Environ Med, 54, 889-896.

DUCHARME, L. J,, KNUDSEN, H. K., ABRAHAM, A. J. \& ROMAN, P. M. 2010. Counselor attitudes toward the use of motivational incentives in addiction treatment. Am J Addict, 19, 496503.

EFFECTIVE PUBLIC HEALTH PRACTICE PROJECT. 2009. Quality Assessment Tool for Quantitative Studies [Online]. Available: http://www.ephpp.ca/PDF/Quality\%20Assessment\%20Tool 2010 2.pdf.

GILES, E. L., ROBALINO, S., MCCOLL, E., SNIEHOTTA, F. F. \& ADAMS, J. 2014. A systematic review, meta-analysis and meta-regression of effectiveness of financial incentives and penalties for encouraging healthy behaviours. PLOS ONE, 9, 1-16.

GOEL, V. 2012. Nudging for health: do we need financial incentives? Healthc Pap, 12, 23-26; discussion 64-66.

GRANT, R. W. 2002. The ethics of incentives: historical origins and contemporary understandings. Econ Philos, 111-139.

GRANT, R. W. 2006. Ethics and incentives: a political approach. Am Polit Sci Rev, 100, 29-39.

KOWAL, E. 2006. Mutual obligation and Indigenous health: thinking through incentives and obligations. Med J Austr, 184, 292-3.

HALPERN, S. D., MADISON, K. \& VOLPP, K. G. 2009. Patients as mercenaries?: The ethics of using financial incentives in the war on unhealthy behaviors. Circ Cardiovasc Qual Outcomes, 2, 514-6. 
HAVEMAN, R. H. 2010. Principles to guide the development of population health incentives. Prev Chronic Dis, 7, A94.

HIGGINS, J. W., COOKSON, S., HASTINGS-JAMES, C. \& FRAZER, A. 2012. Redeeming behaviours: a push, not a shove. Healthc Pap, 12, 42-47; discussion 64-66.

HODDINOTT, P., MORGAN, H., MACLENNAN, G., SEWEL, K., THOMSON, G., BAULD, L., YI, D., LUDBROOK, A. \& CAMPBELL, M. K. 2014. Public acceptability of financial incentives for smoking cessation in pregnancy and breast feeding: a survey of the British public. BMJ Open, 4, 9.

HORWITZ, J. R., KELLY, B. D. \& DINARDO, J. E. 2013. Wellness incentives in the workplace: cost savings through cost shifting to unhealthy workers. Health Aff, 32, 468-476.

JOHNSTON, M. \& SNIEHOTTA, F. F. 2010. Financial incentives to change behaviour. J Health Serv Res Pol, 15, 131.

KANE, R., JOHNSON, P., TOWN, R. \& BUTLER, M. 2004. A structured review of the effect of economic incentives on consumers' preventive behavior. Am J Prev Med, 27, 327-352.

KAVANAGH, J., STANSFIELD, C. \& THOMAS, J. 2009. Incentives to improve smoking, physical activity, dietary and weight management behaviours: a scoping review of the research evidence. London: Institute of Education.

KENNEDY, M. 2012. To nudge or not to nudge--that is not the question. HealthcarePapers, 12, 48-52; discussion 64-66.

KIM, A., KAMYAB, K., ZHU, J. \& VOLPP K. 2011. Why are financial incentives not effective at influencing some smokers to quit? Results of a process evaluation of a worksite trial assessing the efficacy of financial incentives for smoking cessation. J Occup Environ Med, $53,62-67$.

KLEIN, E. 2012. Redefining the clinical relationship in the era of incentives. Am J Bioeth, 12, 2, 26-27.

KLEIN, E. \& KARLAWISH. J. 2010. Challenges and opportunities for developing and implementing incentives to improve health-related behaviors in older adults. J Am Geriatr Soc, 58, 1758-1763. 
LAGARDE, M., HAINES, A. \& PALMER N. 2007. Conditional cash transfers for improving uptake of health interventions in low- and middle-income countries: a systematic review. JAMA, 298, 1900-10.

LAWSON, J. \& HOWARD, B. 2012. Why UFI nudges will get stuck in the policy process. Healthc Pap, 12, 53-57; discussion 64-66.

LESSER, L. L. \& PUHL, R. M. 2014. Alternatives to monetary incentives for employee weight loss. Am J Prev Med, 46, 429-431.

LEWIS, M. W. 2008. Application of contingency management-prize reinforcement to community practice with alcohol and drug problems: a critical examination. Beh Social Issues, 17, 119-138.

LOEPPKE, R. 2012. Guidance for a reasonably designed, employer-sponsored wellness program using outcomes-based incentives. J Occup Environ Med, 54, 889-896.

LONDON, A. J, BORASKY, D. A. Jnr., BHAN, A. \& Ethics Working Group of the H.I.V Prevention Trials Network. 2012. Improving ethical review of research involving incentives for health promotion. PLoS Med / Public Library of Science, 9, e1001193.

LONG, J. A., HELWEG-LARSEN, M. \& VOLPP, K. G. 2008. Patient opinions regarding 'pay for performance for patients'. J Gen Intern Med, 23, 1647-52.

LUNZE, K. \& PAASCHE-ORLOW, M. K. 2013. Financial incentives for healthy behavior: ethical safeguards for behavioral economics. Am J Prev Med, 44, 659-65.

LUYTEN, J., DORGALI, V., HENS, N. \& BEUTELS, P. 2013. Public preferences over efficiency, equity and autonomy in vaccination policy: an empirical study. Soc Sci Med, 77, 84-9.

LUYTEN, J., D. V., HENS N, BEUTELS P. 2013. Public preferences over efficiency, equity and autonomy in vaccination policy: an empirical study. Soc Sci Med, 77, 84-89.

LUYTEN J, VANDEVELDE, A., VAN DAMME, P. \& BEUTELS, P. 2011. Vaccination policy and ethical challenges posed by herd immunity, suboptimal uptake and subgroup targeting. Public Health Ethics, 4, 280-291.

LYNAGH, M., BONEVSKI, B., SYMONDS, I. \& SANSON-FISHER, R. W. 2011. Paying women to quit smoking during pregnancy? Acceptability among pregnant women. Nicot Tob Res, 13, 102-1036. 
MADISON, K. M., VOLPP, K. \& HALPERN, S. D. 2011. The law, policy, and ethics of employers' use of financial incentives to improve health. J Law Med Ethics, 39, 450-468.

MALONE, S. W. \& JASON, L. 1990. Using incentives, lotteries, and competitions in work-site smoking cessation interventions. Drug Alcohol Prev, 313-337.

MANTZARI, E., VOGT, F. \& MARTEAU, T. M. 2012. The effectiveness of financial incentives for smoking cessation during pregnancy: is it from being paid or from the extra aid? $B M C$ Pregnancy Childbirth, 12, 24.

MARTEAU, T., ASHCROFT, R. \& OLIVER, A. 2009. Using financial incentives to achieve healthy behaviour. BMJ, 338, 983-985.

MARTEAU, T. M., OLIVER, A. \& ASHCROFT, R. E. 2008. Changing behaviour through state intervention. BMJ, 337.

MCCORMACK, R. 1996. Provider disclosure of financial incentives in managed care: Pros and cons. Bioethics Forum. Spr, 12, 21-24.

MEADS, D. M., MCCABE, C., CAMIDGE, D. C., HILL, K. M., HOUSE, A. O. \& HULME, C. T. 2013. A contingent valuation survey of user financial incentives for health behaviour change. Value Health, 16 (3), A11.

MEREDITH, S. E., GRABINSKI, M. J. \& DALLERY, J. 2011. Internet-based group contingency management to promote abstinence from cigarette smoking: a feasibility study. Drug Alcohol Depend, 118, 23-30.

MEREDITH, S. E., JARVIS, B. P., RAIFF, B. R., ROJEWSKI, A. M., KURTI, A., CASSIDY, R. N., ERB, P., SY, J. R. \& DALLERY, J. 2014. The ABCs of incentive-based treatment in health care: $A$ behavior analytic framework to inform research and practice. Psychol Res Behav Manag, 7, 103-114.

MHURCHU, C. N., EYLES, H., DIXON, R., MATOE, L., TEEVALE, T. \& MEAGHER-LUNDBERG, P. 2011. Economic incentives to promote healthier food purchases: exploring acceptability and key factors for success. Health Promot Int, 27, 331-341.

MOHER, D., LIBERATI, A., TETZLAFF, J. \& ALTMAN, D. G. 2009. Preferred reporting items for systematic reviews and meta-analyses: The PRISMA statement. PloS Med, 6.

NOBLIT, G. W., HARE, R. D. \& VAN MAANEN, J.(1988) Meta-ethnography: Synthesizing qualitative studies (qualitative research methods), London, SAGE Publications Ltd. 
O'DONNELL, M. P. 2012. Financial incentives for workplace health promotion: What is equitable, what is sustainable, and what drives healthy behaviors? Am J Health Promot, 26, iv-vii.

OLIVER, A. 2009. Can financial incentives improve health equity? BMJ, 339, b3847.

OLIVER, A. 2012. A nudge too far? A nudge at all? On paying people to be healthy. Healthc Pap, $12,8-16$.

OLIVER, A. \& BROWN, L. D. 2012. A consideration of user financial incentives to address health inequalities. J Health Polit Policy Law, 37, 201-226.

PARK, J. D, MITRA, N. \& ASCH, D. A. 2012. Public opinion about financial incentives for smoking cessation. Prev Med, 55, Suppl. S41-S45.

PARKE, H., ASHCROFT, R., BROWN, R., MARTEAU, T. M. \& SEALE, C. 2013. Financial incentives to encourage healthy behaviour: An analysis of UK media coverage. Health Expect, 16, 292304.

PAUL-EBHOHIMHEN, V. \& AVENELL, A. 2008. Systematic review of the use of financial incentives in treatments for obesity and overweight. Obesity Rev, 9, 355-367.

PEARSON, S. D. \& LIEBER, S. 2009. Financial penalties for the unhealthy? Ethical guidelines for holding employees responsible for their health. Health Aff, 28, 845-52.

PETRY, N. M. 2010. Contingency management treatments: controversies and challenges. Addict, 105, 1507-1509.

PETTICREW, M. \& ROBERTS, H. 2005. Systematic Reviews in the Social Sciences A Practical Guide, Oxford, Blackwell Publishing Ltd.

POPAY, J. 2008. Should disadvantaged people be paid to take care of their health? No. BMJ, $337,141$.

PROMBERGER, M., BROWN, R., ASHCROFT, R. E. \& MARTEAU, T. M. 2011. Acceptability of financial incentives to improve health outcomes in UK and US samples. J Med Ethics, 37, 682-687.

PROMBERGER, M., DOLAN, P. \& MARTEAU, T. M. 2012. "Pay them if it works": discrete choice experiments on the acceptability of financial incentives to change health related behaviour. Soc Sci Med, 75, 2509-2514. 
RAIFF, B. R., JARVIS, B. P., TURTURICI, M. \& DALLERY, J. 2013. Acceptability of an internet-based contingency management intervention for smoking cessation: Views of smokers, nonsmokers, and healthcare professionals. Exp Clin Psychopharmacol, 21, 204-213.

RITTER, A. \& CAMERON, J. 2007. Australian clinician attitudes towards contingency management: comparing down under with America. Drug Alcohol Depend, 87, 312-315.

ROBISON, J. I. 1998. To reward? ... or not to reward?: Questioning the wisdom of using external reinforcement in health promotion programs. Am J Health Promot, 13, 1-3.

ROOZEN, H. G. 2009. [Commentary] Legitimizing the medical prescription of money. Addict, 104, 1539-1540.

SCHMIDT H. 2008. Bonuses as incentives and rewards for health responsibility: a good thing? J Med Phil, 33, 198-220.

SCHMIDT, H. 2012. Wellness incentives, equity, and the 5 groups problem. Am J Public Health, 102, 49-54.

SCHMIDT, H., ASCH, A. \& HALPERN, S.D. 2012. Fairness and wellness incentives: what is the relevance of the process-outcome distinction? Prev Med, 55, S118-S123.

SCHMIDT, H., GERBER, A. \& STOCK, S 2009. What can we learn from German health incentive schemes? BMJ, 339, b3504.

SCHMIDT, H., VOIGT, K. \& WIKLER, D. 2009. Carrotts, sticks and health care reform - Problems with wellness incentives. $N$ Engl J Med.

SERXNER, S. A. 2013. A different approach to population health and behavior change:Moving from incentives to a motivation-based approach. Am J Health Promot: AJHP, 27, TAHP4TAHP7.

SINDELAR, J. L. 2008. Paying for performance: the power of incentives over habits. Health Econ, $17,449$.

STEPHENS, C. 2014. Paying the piper: additional considerations of the theoretical, ethical and moral basis of financial incentives for health behaviour change. Int J Behav Med, 21, 202-205.

STRAUSS, A. L. 2003. Qualitative analysis for social scientists, Cambridge, Cambridge University Press. 
SWANN, C., CARMONA, C., RYAN, M., RAYNOR, M., BARIS, E., DUNSDON, S., HUNTLEY, J. \& KELLY, M. P 2010. Health systems and health-related behaviour change: a review of primary and secondary evidence. Copenhagen, National Institute for Clinical Excellence.

TEN HAVE, M., VAN DER HEIDE, A., MACKENBACH, J. P. \& DE BEAUFORT, I. D. 2013. An ethical framework for the prevention of overweight and obesity: a tool for thinking through a programme's ethical aspects. Eur J Public Health, 23, 299-305.

TERRY, P. E. 2013. The use of incentives for "nondiscriminatory" wellness programs: Three questions answered and three questions still wanting. Am J Health Promot, 27, taph10taph12.

TERRY, P.E. \& ANDERSON, D. 2011. Finding common ground in the use of financial incentives for employee health management: a call for a progress-based approach. Am J Health Promot, 26, ev-evii.

THE COCHRANCE COLLABORATION. 2011. Cochrane handbook for systematic reviews of interventions [online]. Available http://handbook.cochrane.org/.

THOMSON, G., DYKES, F., HURLEY, M. \& HODDINOTT, P. 2012. Incentives as connectors: insights into a breastfeeding incentive intervention in a disadvantaged area of North-West England. BMC Pregnancy Childbirth, 12, 22.

THOMSON, G., MORGAN, H., CROSSLAND, N., BAULD, L., DYKES, F., HODDINOTT, P. \& ON BEHALF OF THE, B. T. 2014. Unintended Consequences of Incentive Provision for Behaviour Change and Maintenance around Childbirth. PLOS ONE, 9, e111322.

TUTEN, L., JONES, H. E., SCHAEFFER, C. M. \& STITZER, M. L. 2012. Contingency management to improve treatment outcomes. Tuten, L Michelle, 109-120.

VOIGT, K. 2012. Incentives, health promotion and equality. Health Econ Policy Law, 7, 263-283.

VOLPP, K. G., ASCH, D.A., GALVIN, R. \& LOEWENSTEIN, G. 2011. Redesigning employee health incentives: Lessons from behavioral economics. New Engl J Med, 365, 388-390.

VOLPP, K. G. \& GALVIN, R. 2014. Reward-based incentives for smoking cessation: How a carrot became a stick. JAMA, 311, 909-10.

VOLPP, K. G., PAULY, M. V., LOEWENSTEIN, G. \& BANGSBERG, D. 2009. P4P4P: An agenda for research on pay-for-performance for patients. Health Aff, 28, 206-214. 
WALL, J., NI MHURCHU, C., BLAKELY, T., RODGERS, A. \& WILTON, J. 2006. Effectiveness of monetary incentives in modifying dietary behavior: A review of randomized, controlled trials. Nutr Rev, 64, 518-531.

WHITE, M., ADAMS, J. \& HEYWOOD, P. 2009. How and why do interventions that increase health overall widen inequalities within populations? Social Inequal Public Health, 65-82.

WU, J. 2012. Rewarding healthy behaviors--pay patients for performance. Ann Fam Med, 10, 261-3. 


\section{FIGURE LEGENDS}

Figure 1 PRISMA flow diagram

Figure 2 Quality assessment of qualitative empirical papers

Figure 3 Citation mapping - cited by another included paper

\section{TABLE LEGENDS}

Table 1 Summary of aims, methods and participants in empirical studies included in the review

Table 2 Summary of scholarly writing included in the review

Table 3 Quality assessment of quantitative empirical papers

Box 1 Quotations to illustrate the 'Fair exchange' theme

Box 2 Quotations to illustrate the 'Design and delivery of HPFI' theme

Box 3 Quotations to illustrate the 'Effectiveness and cost-effectiveness' theme

Box 4 Quotations to illustrate the 'Recipients of HPFI' theme

Box 5 Quotations to illustrate the 'Impact of HPFI on individuals and wider society' theme

Appendix A Completed PRISMA checklist

Appendix B Medline search strategy 